[Denpun Kagaku, Vol.38, No. 2, p. 137 139 (1991)]

\title{
Structure and Catalytic Implications of Taka-Amylase $\mathrm{A}^{\dagger}$
}

\author{
Yoshiki MatsuURA,* Masami KusunOKI* and Masao KAKUdo** \\ * Institute for Protein Research, Osaka University \\ (3-2, Yamadaoka, Suita, Osaka 565, Japan) \\ ** Hyogo Industrial Research Institute \\ (5-10-1, Shimoyamatedori, chuouku, Kobe 650, Japan)
}

\begin{abstract}
Taka-amylase has a $(\beta \alpha)_{8}$ barrel structure and the active site is located at the C-terminal end of a $\beta$-strand as reported earlier. In this paper, we describe about the direction of substrate amylose binding with respect to the barrel structure. A possible mechanism of hydrolysis is also proposed, in which Glu 230, Asp 297 and Asp 206 located near the active site are essentially involved.
\end{abstract}

Taka-amylase $\mathrm{A}$ (TAA) is an $\alpha$-amylase produced by Aspergillus oryzae. The threedimensional structure of this protein has been determined at $3 \AA$ resolution. ${ }^{1)}$ The structure refinement is now under way and the results will be reported elsewhere. Here we briefly describe some topics concerning the action of amylases from the stereochemical points of view.

\section{BINDING MODE OF AMYLOSE ON THE ENZYME}

In the earlier paper we described a hypothetical substrate binding mode on the Takaamylase molecule. The model was built based on the study of model fitting between amylose and the observed structure of TAA. In that model, the orientation of the reducing and non-reducing end of the substrate was also defined. A schematic binding mode of an amylose is shown in Fig. 1 with the topological representation of the $(\beta \alpha)_{8}$ barrel structure in the enzyme. The orientation of the substrate shown here also reasonably explains the mode of actions in the three-dimensional structures of CGTase $^{2)}$ and $\beta$-amylase, ${ }^{3)}$ each contains also the barrel structure. Thus it is likely that amylose binds in the same way with res-

† "Proceedings of the Amylase Symposium, 1990" pect to the $(\beta \alpha)_{8}$ structure in these enzymes. It has been suggested on the basis of sequence comparisons that $\alpha$-amylases may commonly possess the same barrel structure. ${ }^{4)}$ Similar $(\beta \alpha)_{8}$ structure has been found in fifteen functionally different enzymes analyzed by $\mathrm{X}$-ray diffraction, and its significance has been discussed from the evolutional point of view. ${ }^{5)}$ It is not obvious at present that the binding of amylose on the $(\beta \alpha)_{8}$ structure is a result of the specific interaction between the barrel structure and amylose.

\section{CATALYTIC RESIDUES}

In the structure analysis of TAA, the catalytic residues which may be directly involved to break an $\alpha$-1, 4-glucosidic linkage were shown to be Glu230 and Asp297, as acid and base, respectively. Later in the structure analysis of hog pancreatic $\alpha$-amylase, ${ }^{6)}$ it was shown that the corresponding residues are Asp 197 (Asp 206 in TAA) and Asp 300 (Asp 297 in TAA), respectively. More recently in the structure analysis of Taka-amylase, ${ }^{7)}$ it was proposed that the catalytic residues may be Asp 206 and Glu 230. The positions of these residues are also shown in Fig. 1; Glu 230 lies at the end of the 5 th $\beta$-strand and Asp 206 at the end of the 4 th $\beta$-strand, while Asp 297 at the loop region between the 7 th $\beta$-strand and 


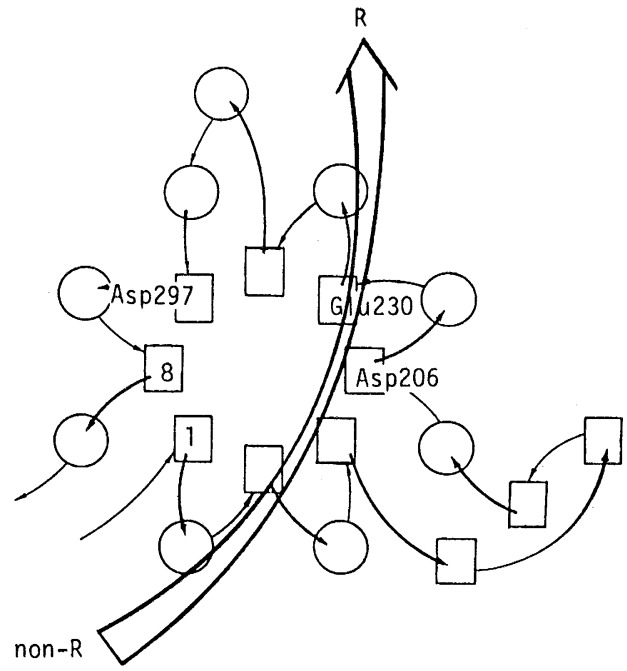

Fig. 1. Schematic binding mode of amylose on the $(\beta \alpha)_{8}$ structure of TAA.

The barrel is seen from the $\mathrm{C}$-terminal end of the $\beta$-strand. $\mathrm{R}$ and non- $\mathrm{R}$ denote the reducing and non-reducing end of amylose, respectively. Putative catalytic residues are also shown.

the 7 th $\alpha$-helix in the $(\beta \alpha)_{8}$ barrel structure. All of these residues are found in well-conserved regions in the amino acid sequences of $\alpha$-amylases. Recent studies of mutagenesis of $\alpha$ amylases $^{8-10)}$ have shown that the replacement of any one of these three residues results in complete loss of their enzyme activities, while others are not. A biochemical characterization of such a mutant enzyme, ${ }^{9}$ however, showed that glutamate is more likely to be the acid catalyst than aspartate is, as proposed in the structure analysis of TAA." ${ }^{1}$ Since Glu 230 and Asp 206 are positioned in close contact with each other in the three-dimensional structure of TAA, the modification of one of these residues must strongly affect the other. But Asp 206 is also expected to be essentially involved in the catalysis.

Hydrophobic residues are constantly found in the region just after Glu 230 in TAA and the corresponding regions of other $\alpha$-amylases. This seems necessary to provide hydrophobic environment around the acid catalyst residue to raise its $\mathrm{p} K_{\mathrm{a}}$ value. Near this region, there is a bound calcium ion which is coordinated by the side chains of Asn 121 and Asp 175, and the main chain carbonyls of Glu 162 and His 210. All these residues except Glu 162 have been shown to be conserved in $\alpha$-amylases. ${ }^{4)}$ The calcium ion may play an essential role in $\alpha$-amylases to maintain the architecture of the active cleft.

\section{CATALYTIC MECHANISM}

Based on the studies of three-dimensional structures and the results of mutagenesis of $\alpha$-amylases, we must consider at least three residues (Asp 206, Glu 230, Asp 297 in TAA) are critically involved in the catalytic reactions. One possible mechanism of hydrolysis by TAA is schematically shown in Fig. 2 . On binding substrate amylose at the catalytic site, the hydrogen atom of Glu230 is added to the oxygen atom to break the glucosidic bond. After releasing the non-reducing side fragment of amylose, a water molecule might be introduced to make a bifurcated hydrogen bond with the carboxyl anions of Glu 230 and Asp 206. The bifurcated hydrogen atom will reduce the repulsion between two anions. The carboxyl anion of Asp 297 may stabilize the carbonium cation intermediate. In the next step, the bound water molecule is split into a proton and a hydroxyl anion to form a hydrated Glu 230 and a cleaved reducing side fragment of amylose. Then the new substrate is bound to the catalytic site reproducing the initial substrate bound step.

In considering the catalytic mechanism of $\alpha$ amylase, the essential points are:

a) Where the water molecule comes from and how it is introduced.

b) Whether the carbonium cation is formed and stabilized by the base anion, or a covalentlike bond is formed between cleaved end of amylose and the base residue.

\section{FUTURE PROSPECTS}

Unambiguous assignment of the catalytic residues and the experimental determination of the productive binding mode of the substrate are expected in future. One possible approach to solving these questions is the structure analysis of the complex of the substrate and a 


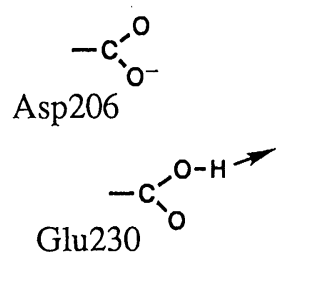<smiles>CC1CCCCO1</smiles><smiles>CC1CC[Ge](C)(O)OC1</smiles><smiles>CC(C)O[18O]</smiles><smiles>[CH]=C</smiles><smiles>CC([O-])O</smiles><smiles>CCCOC(C)O</smiles>

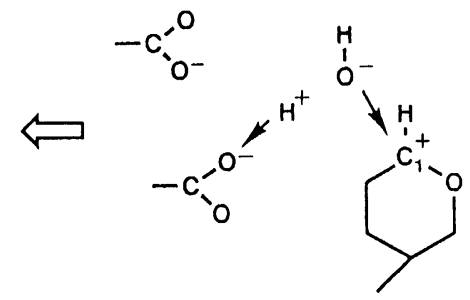<smiles>CCCCCCCCO</smiles><smiles>COC(C)O</smiles><smiles>[C]=C</smiles>

Fig. 2. A possible mechanism of hydrolysis by Taka-amylase.

The initial substrate bound step is shown in the upper-left side. In this mechanism, Asp206 is working to introduce a water molecule.

mutant enzyme that is inactivated for the degradation while binding the substrate productively. A milli- or microsecond snapshot X-ray analysis using synchrotron radiation sources, ${ }^{11}$ on the other hand, has a possibility to reveal the structure of the transition state of the enzyme-substrate complex.

\section{REFERENCES}

1) Y. MAtSUURA, M. KuSUNOKI, W. HARADA and M. KAKUDO : J. Biochem., 95, 697-702 (1984).

2) M. Kubota, Y. MATSUURA, S. SAKai and Y. KATSUBE : in Abstracts, ISC, Abstract No. P 46 (1990).

3) B. Mikami, T. Shibata, M. Hirose, S. Aibara, M. SATO, Y. KATSUBE and Y. MORITA : in $A b$ stracts, ISC, Abstract No. P 47 (1990).

4) E. A. MACGREGOR and B. SVENSSON : Biochem. J., 259, 145-152 (1989).
5) L. LEBIODA and B. STEC : Nature, 333, 683-686 (1988).

6) G. Buisson, E. DueE, R. HASER and F. PAyAN : EMBO J., 6, 3909-3916 (1987).

7) E. BOEL, L. BRADY, A. M. BRzozowski, $Z$. DEREWANDA, G. G. DODSON, V. J. JENSEN, S. B. Petersen, H. Swift, L. Thim and H. F. WOLDIKE : Biochemistry, 29, 6244-6249 (1990).

8) K. Tsusaki, M. Kubota, S. Sakai, M. KuRIMOTO and Y. TsujISAKA : in Abstract, Annu. Meet. Soc. Ferment. Tech. Jpn., 824 (1989).

9) K. TAKASE, T. MATSUmoto, H. Mizuno and K. YAMANE : Protein Eng. 89, Abstract SIII-p08 (1989)

10) T. KURIKI and T. IMANAKA : in Abstract, Annu. Meet. Soc. Agric. Biol. Chem. Jpn (1990).

11) J. HAJDU and L. N. JOHNSON : Biochemistry, 29, 1669-1678 (1990).

(Received December 27, 1990) 